\title{
O COMPONENTE CURRICULAR ASPECTOS DA VIDA CIDADÃ (AVC) E O GOVERNAMENTO DE SUBJETIVIDADES
}

\author{
Vilma Nonato de BRÍCIO' \\ Campus Universitário de Abaetetuba/UFPA \\ vilma@ufpa.br \\ Josenilda MAUÉS ${ }^{2}$ \\ ICED/UFPA \\ jomaues@ufpa.br
}

Resumo: $O$ presente texto problematiza a constituição do currículo escolar, ao analisar as condições de emergência do componente curricular Aspectos da Vida Cidadã (AVC) criado na Escola em Regime de Convênio de Ensino Fundamental e Médio São Francisco Xavier que funciona em regime de convênio entre a Secretaria Estadual de Educação do Estado do Pará (SEDUC) e a Diocese de Abaetetuba com o objetivo de governar subjetividades. Foram analisados enunciados de documentos da escola, os quais permitiram rastrear alguns discursos

1 Graduada em Pedagogia pela Universidade Federal do Pará (2002), Mestre em Educação pela Universidade Federal do Pará. Doutoranda em Educação pela Universidade Federal do Pará. Professora Assistente II da Universidade Federal do Pará - Campus Universitário de Abaetetuba. Vice-Líder do Grupo de Pesquisa Transversalizando.vilma@ufpa.br

2 Possui graduaçãoGraduada em Pedagogia pela Universidade Federal do Pará (1980), Mestrado Mestre em Educação: História, Política, Sociedade pela Pontifícia Universidade Católica de São Paulo (1993), e Doutorado Doutora em Educação (Currículo) pela Pontifícia Universidade Católica de São Paulo (1998). Professora Adjunta do Instituto de Educação, do Programa de PósGraduação em Educação da Universidade Federal do Pará. Líder do Grupo de Pesquisa DIFERE. Editora da Revista Artifícios. jomaues@ufpa.br 
sobre a invenção de AVC e as formas como se tornou um dos espaços legitimados na escola para produzir subjetividades governadas.

Palavras-chave: Currículo. Subjetividade. Governamentalidade.

Abstract: This paper discusses the creation of the school curriculum, to analyze the emergency conditions of the curricular component aspects of Citizen Life (AVC) established by the School of Basic Education Agreement Scheme and Middle São Francisco Xavier that works in partnership arrangements between the Secretariat State of Pará State Education (SEDUC) and the Diocese of Abaetetuba in order to govern subjectivities. Set of school documents were analyzed, which it tracks some speeches about the invention of stroke and the ways became one of the legitimate spaces in the school to produce subjectivities governed.

Keywords: Curriculum. Subjectivity. Governmentality.

\section{Balizamentos iniciais}

Este artigo aciona parte das incursões realizadas em uma pesquisa de mestrado que problematizou as práticas objetivantes das relações de gênero e sexualidade, produzidas no componente curricular Aspectos da Vida Cidadã (AVC), constituído na "Escola em Regime de Convênio de Ensino Fundamental e Médio São Francisco Xavier”. O “Colégio São Francisco Xavier” (CSFX), como é mais conhecido, é um estabelecimento de ensino que funciona em regime de convênio entre a Secretaria Estadual de Educação do Estado do Pará (SEDUC) e a Diocese de Abaetetuba ${ }^{3}$.

A pesquisa foi balizada pela seguinte questão de investigação: Quais discursos sobre gênero e sexualidade

3 O município de Abaetetuba fica situado no nordeste do estado do Pará. Abaetetuba possui tem 16 escolas estaduais e 03 três em regime de convênio entre a Diocese de Abaetetuba e a SEDUC. Além do CSFX, as escolas Cristo Redentor e Cristo Trabalhador, incluíram AVC no currículo escolar e segundo a diretora o CSFX propôs a SEDUC que estendessem sua oferta para toda Rede Estadual de Ensino. 
são produzidos no componente curricular Aspectos da Vida Cidadã (AVC)? E se utilizou operadores teórico-metodológicos foucaultianos (FOUCAULT, 1995, 2004, 2006) que ofereceram ferramentas analíticas para problematizar os enunciados de documentos levantados e recortados de um conjunto heterogêneo de práticas, os quais nos permitiram rastrear séries discursivas e realizar perguntas a respeito das formas de normalização dos sujeitos em $\mathrm{AVC}^{4}$. No CSFX, coexistem duas orientações administrativas, pedagógicas e curriculares, uma laica e uma religiosa, que promovem alianças e tensões na composição de forças que constituem as práticas sobre currículo e sobre as relações de gênero e sexualidade.

Parao momento, apresentamosapenasalgumasdiscussões resultantes desta pesquisa sobre a organização curricular do CSFX que resultou na criação do componente curricular AVC. Desste modo, organizamos nossos argumentos em torno de dois eixos: Currículo: dispositivo de poder disciplinar e de biopolítica e a constituição do componente curricular Aspectos da Vida Cidadã (AVC).

2. Currículo: dispositivo de poder disciplinar e de biopolítica

Para analisar a constituição do componente curricular Aspectos da Vida Cidadã (AVC) e as subjetividades por ele produzidas é preciso problematizar o currículo como um

\footnotetext{
4 Documentos que formaram o corpus de análise da pesquisa: O Regimento Escolar do CSFX (2000), o Relatório PROGESTÃO (2004), o Projeto Político Pedagógico (2008), o Código de Ética e Conduta do CSFX (2007), o Conteúdo Programático das Disciplinas (2009) e o Relato de experiência de um projeto sobre gênero e sexualidade realizado no CSFX enviado ao $5^{\circ}$ Prêmio de Igualdade de Gênero intitulado "Desmistificando a sexualidade em Rodas de Conversas" (2009) e as entrevistas realizadas com 03 três docentes da disciplina AVC, que assinaram junto com a direção da escola, o Termo de Consentimento Livre e Esclarecido (TCLE).
}

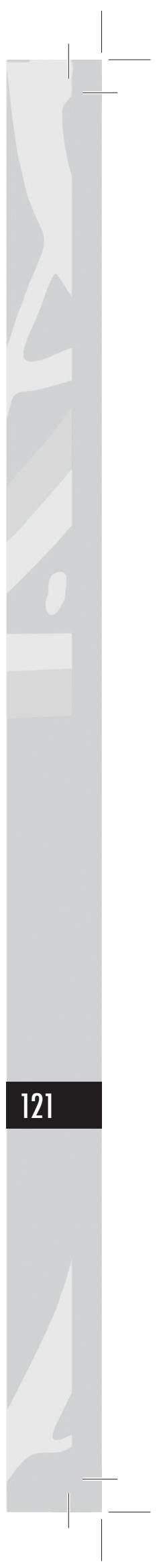




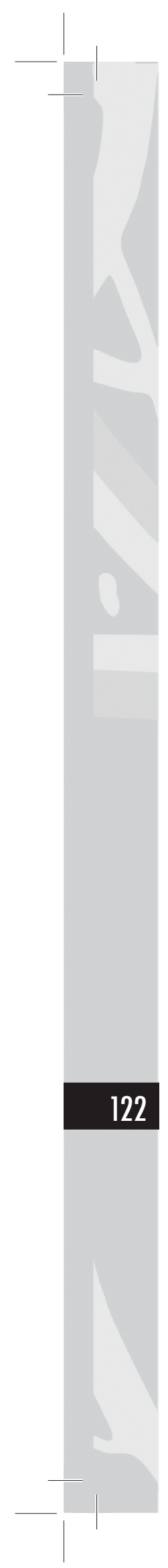

dispositivo que põem em funcionamento estratégias disciplinares e biopolíticas que se articulam e compõem forças nos regimes de verdades engendradas nos currículos escolares ${ }^{5}$.

Foucault não foi um intelectual da educação, muito menos um curriculista, porém, ao analisar as instituições modernas, incluiu a escola, como instituição disciplinar e de forma indireta o currículo, ao analisar a organização da escola, os exames. A escola moderna, para Foucault (2004), é marcada pelas relações de poder disciplinares, que por meio da proliferação de discursos normalizadores constituem a civilização moderna, pois "Todo sistema de educação é uma maneira política de manter ou modificar a apropriação dos discursos, com os saberes e poderes que eles trazem consigo" (FOUCAULT, 2004, p. 43-44).

Ao analisar a educação como produtora e distribuidora de discursos envolvidos com saberes e poderes específicos, Foucault (2004) analisa o sistema de ensino na qualificação e fixação de papéis para os sujeitos que falam, pois tais discursos pedagógicos engendram formas de regulamentação e de controle dos sujeitos ${ }^{6}$. As escolas ou sistemas de ensino fazem circular os discursos que interessam, contribuindo para a constituição de corpos governáveis. "O que é afinal um sistema de ensino senão uma ritualização da palavra; senão uma qualificação e uma fixação dos papéis para os sujeitos que falam; senão a constituição de um grupo doutrinário ao menos difuso; senão uma distribuição e uma apropriação do discurso com seus poderes e seus saberes?" (FOUCAULT, 2004, p. 44-45). O sistema de ensino e a escola

5 Os regimes de verdade são fabricados a partir de "[...] vários discursos e lugares de poder, formam uma espécie de pontilhado, o qual funciona como se se tratasse de virtualidades prefiguradas" (VEYNE, 2008, p. 266).

6 A despeito das diferenças entre as escolas que Foucault analisou e a configuração das escolas na contemporaneidade, interessa-nos, centralmente, o raciocínio acerca da operação constitutiva das práticas discursivas em suas regras de produção e circulação e os regimes de verdade instituídos pelos discursos circulantes em diferentes espaços e instituições, entre as quais as escolares. 
utilizam o currículo para construir práticas articulando saber e poder na constituição de subjetividades por meio do controle do tempo e do espaço. A escola por meio do currículo

\section{[...] contribuiu decisivamente para a crescente abstração} do tempo e do espaço e para o estabelecimento de novas articulações entre ambos. Isso foi tão mais decisivo na medida em que tanto a escola fez do currículo o seu eixo central quanto ela própria tomou a si a tarefa de educar setores cada vez mais amplos e numerosos da sociedade. (VEIGA-NETO, 2002, p. 163).

Para exercer o domínio do tempo, do espaço, dos sujeitos, o currículo é atravessado por relações de poder, mas um poder capilar, que age sutilmente, de forma muito eficaz. $\mathrm{Na}$ perspectiva foucaultiana, o poder é considerado descentralizado e difuso, contrapondo-se àa noção moderna de poder, em geral representado como domínio, força, controle, contendo significados unicamente negativos. Mas, o poder "[...] não pesa só como uma força que diz não, mas que de fato ele permeia, produz coisas, induz ao prazer, forma saber, produz discurso" (FOUCAULT, 2006, p. 8). A partir dessa concepção de poder não há lugar para a noção de um currículo essencializado, pois, no exercício do poder, entram em jogo diferentes técnicas para controlar e dominar os sujeitos, que, assim como são aceitas de forma passiva, também são contestadas, resistidas, evidenciando a circularidade do poder.

O currículo como um dispositivo de poder, "[...] envolve formas de conhecimento cujas funções consistem em regular e disciplinar o indivíduo" (POPKEWITZ, 2002, p. 186), através da seleção, organização e imposição do conhecimento objetivando a regulação e o controle de si em dada sociedade ${ }^{7}$. A própria seleção de

7 O dispositivo tem um sentido e função metodológica e é problematizado por Foucault como, “[...] um conjunto decididamente heterogêneo que engloba discursos, instituições, organizações arquitetônicas, decisões regula- 


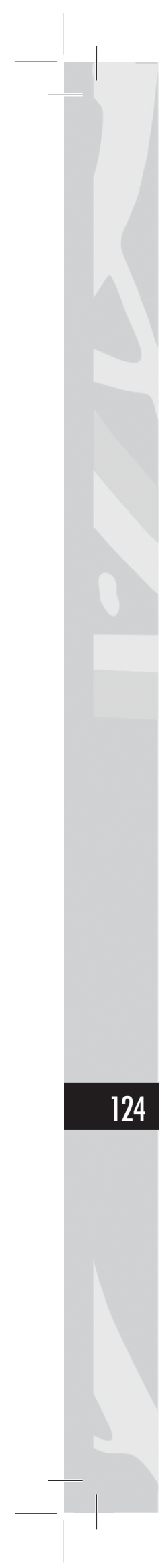

conhecimento para compor o currículo se constitui uma operação de poder, pois alguns conhecimentos são considerados mais válidos, verdadeiros em detrimento de outros, sobretudo aqueles não validados pela ciência. Esses conhecimentos legitimados para fazer parte do currículo nos constituem, moldam as subjetividades, uma vez que esstas são produzidas social e historicamente. "As teorias do currículo deduzem o tipo de conhecimento considerado importante justamente a partir de descrições sobre o tipo de pessoas que elas consideram ideal [...] No fundo das teorias de currículo está, uma questão de "identidade" ou "subjetividade"” (SILVA, 2003, p. 15).

O currículo contribui substancialmente na constituição das subjetividades, daquilo que somos, pois "se materializam em diferentes aparatos, com investimentos heterogêneos, envolvendo diferentes práticas discursivas e tecnologias" (MAUÉS, 2004, p. 07), que, juntamente com os conhecimentos relativos às disciplinas escolares, constrói e faz proliferar discursos sobre formas politicamente sancionadas de ser, sentir, pensar, agir, viver. Assim, o currículo disciplina, normatiza e controla os indivíduos, logo, é um dispositivo destinado à produção de sujeitos através de determinadas tecnologias de diferenciação e identificação (LARROSA, 2002).

Na medida em que está irremediavelmente atravessado por regimes de poder, o currículo como forma de governo constrói e faz circular discursos sobre experiências objetivas do mundo, estruturando um campo de ação, através de "regimes de verdade". Esstes se tornam responsáveis em transmitir o conhecimento sobre certas noções particulares, entre as quais de gênero e sexualidade, mas também etnia e raça, nação e região, religião entre outras, que sancionadas, contam como verdade

mentares, leis, medidas administrativas, enunciados científicos, proposições filosóficas, morais, filantrópicas. Em suma, o dito e o não dito são os elementos do dispositivo. O dispositivo é a rede que se pode estabelecer entre estes elementos" (FOUCAULT, 2006, p. 244). 
nas normas e práticas, com vista ao autodisciplinamento e à vigilância constante. "Ligados a uma cadeia sempre incompleta de significantes os currículos [...] apresentam ramificações de linguagem com outros aparatos discursivos que disputam a autoridade de definir o que é válido e verdadeiro para ser ensinado e para conformar determinados tipos de subjetividades" (MAUÉS, 2004, p. 6-7).

Nesse confronto para definir o conhecimento válido, o currículo utiliza diferentes técnicas de poder. Essas técnicas podem ser individualizantes, como a disciplina e técnicas coletivas, como a biopolítica da população, como a definição de um currículo nacional, abrangendo o conjunto da população escolarizável, os estudantes. A constituição do currículo se apoia na disciplina, que "[...] 'fabrica' indivíduos: ela é a técnica específica de um poder que toma os indivíduos ao mesmo tempo como objetos e como instrumentos de seu exercício. [...] é um poder modesto, desconfiado, que funciona a modo de uma economia calculada, mas permanente" (FOUCAULT, 2005c, p. 143). As técnicas disciplinares visam a docilização dos corpos, de modo que cada corpo assuma um lugar determinado no tempo "apropriado" e a organização dos saberes, visando que a classificação, a distribuição e a administração dos saberes escolares sejam minimamente calculadas. A disciplina fabrica "corpos dóceis" utilizando técnicas minuciosas eindividualizantes na escola, onde os educandos "[...] são "vigiados", disciplinados com a justificativa de manter a ordem entre os/as alunos/as e a organização da escola. Assim, horários (de aula, do recreio, da educação física), locais (de aula, de refeição, de esporte, de leitura), são cuidadosamente administrados para "manter a tranquilidade" e inibir "transgressões"” (BRÍCIO, 2007, p. 06).

Esse investimento disciplinar no corpo individual emprega o "olhar hierárquico", para esquadrinhar o espaço escolar, controlar a posição, a classificação, o ordenamento dos corpos. Esse mecanismo de coerção leve, mas constante, permite a internalização de normas e regras, de modo que se constitua um corpo escolarizado, produto de um currículo disciplinador constituído por pedagogias disciplinares que "[...] fazem das

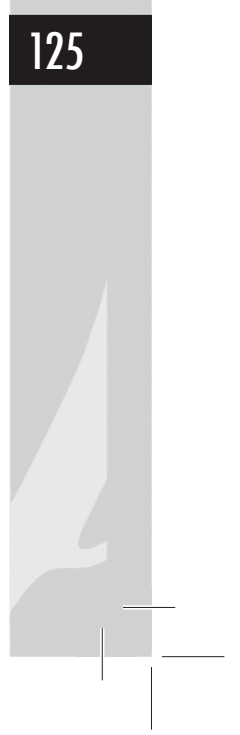




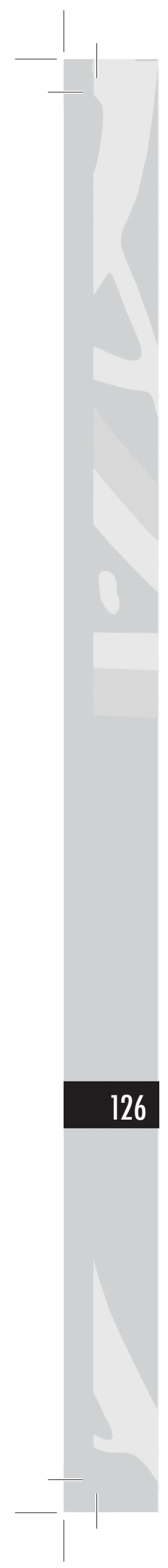

instituições educativas, instituições examinadoras, espaços de observação eminentemente normalizadores e normativos, já que o exame implica duas operações fundamentais: a vigilância hierárquica e a sanção normalizadora" (VARELA, 2002, p. 85), que se interconectarem e permitem decifrar, medir, comparar, hierarquizar e normalizar as subjetividades estudantis. Através de um currículo normalizador e examinador, a escola converte cada estudante em sujeito individual, não somente para discipliná-lo, mas do mesmo modo para corrigi-lo, pois nessa correlação de forças há aceitação, mas também resistências, intensificando as relações de poder, o que demanda além de tecnologias de poder individualizantes, técnicas massificantes, coletivas de poder, para atingir todo o corpo social, ou seja, a população.

Em tempos de grande explosão demográfica e de crescimento do aparelho produtivo, a necessidade de controle do corpo social, do corpo-espécie aumenta. Desste modo, constitui-se um polo de poder designado por Foucault (2005a) de biopolítica, um processo de gestão da vida, de governo das populações, ou seja, processos de regulação da vida das populações por meio de medidas maciças, estimativas estatísticas, intervenções que abrangem todo o corpo social. Em todos os âmbitos a população é alvo de investimentos biopolíticos: na saúde, na demografia, na educação, na moradia, no saneamento básico, na sexualidade, etc. A vida das populações é controlada, regulada por diferentes instituições: sociais, jurídicas, culturais, educacionais, médicas, psicológicas, ou seja, por "[...] mecanismos globais, de agir de tal maneira que se obtenham estados globais de equilíbrio, de regularidade; em resumo de levar em conta a vida, os processos biológicos do homem-espécie e de assegurar sobre eles não uma disciplina, mas uma regulamentação" (FOUCAULT, 2005b, p. 294).

Ao estabelecer uma regulamentação da vida social dos indivíduos, a tecnologia biopolítica garante um domínio da população em colaboração ao controle individual exercido pelo poder disciplinar, uma vez que esses poderes se complementam, não sendo excludentes. Nesste contexto, o currículo pode ser pensado como estratégia de poder que põe em funcionamento tanto o poder disciplinar quanto a biopolítica. De acordo com 
Silva (2003), a noção de currículo emergiu com o objetivo de racionalizar o processo de construção, desenvolvimento e testagem dos processos de ensino-aprendizagem, em conexão com o processo de industrialização e os movimentos imigratórios impulsionadores da massificação da educação. Sua própria constituição é decorrente de várias transformações na sociedade, pois exigiam um controle global da população: a formação de uma burocracia estatal; a educação como objeto de estudo científico; a ampliação da escolarização da população; as preocupações com a manutenção de uma identidade nacional, como resultado das sucessivas ondas de imigração; o processo de industrialização e urbanização.

Desste modo, com o objetivo de “[...] planejar "cientificamente" as atividades pedagógicas e controlá-las de modo a evitar que o comportamento e o pensamento do aluno se desviassem de metas e padrões predefinidos" (MOREIRA; SILVA, 1994, p. 09), o currículo assume configurações de uma tecnologia biopolítica. Ao assumir uma preocupação com a organização e método, o currículo é pensado para o coletivo, de modo que põe em funcionamento ações biopolíticas, porque serve para controlar a população escolarizável.

A configuração atual da sociedade contribui para que o currículo se reafirme como um artifício de ação biopolítica na educação, um artefato de regulação coletiva, pois em tempos de globalização os hábitos, as culturas, as populações e as línguas foram massificados numa tentativa de universalização de nossas sociedades, economias e compreensões de mundo e os currículos nacionais funcionam como uma tecnologia de poder que governa não só os saberes, mas também a conduta das pessoas em escala coletiva, atravessando as populações escolares.

Na década de 1990, a educação e o currículo adquiriram centralidade no processo de reestruturação do Estado brasileiro assumida pela direita, ao combinar o neoliberalismo (econômico) com o neoconservadorismo (moral) (SILVA, 1995). No Brasil, a definição em 1997 pelo Ministério da Educação dos Parâmetros Curriculares Nacionais (PCN) como uma política educacional pode ser analisada como uma estratégia de biopoder, pois

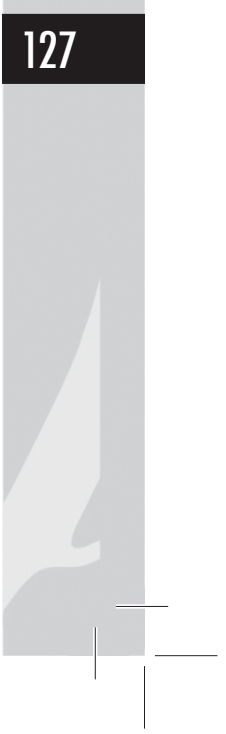




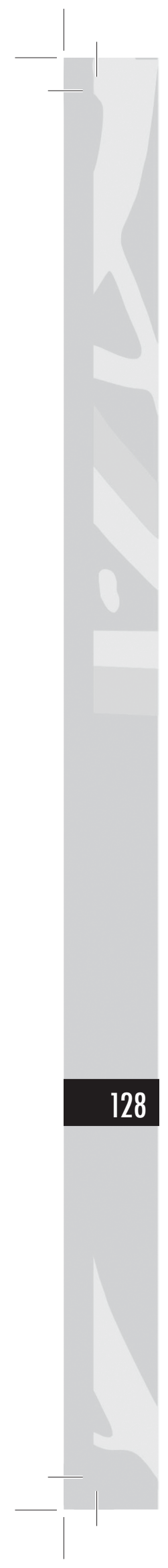

apresenta preocupações individualizantes e totalizantes com os estudantes, de um lado gerenciando a vida escolar em escala nacional de crianças e jovens e de outro disciplinando os corpos individuais. Com a justificativa de cumprir preceitos definidos pela Constituição de 1988, os PCN determinam conteúdos mínimos para o ensino fundamental com a suposta finalidade de assegurar uma formação básica comum, promover o aumento da qualidade de ensino e contribuir com a reformulação curricular empreendida pelos estados e municípios (MOREIRA, 1996). Em nome da educação e da expansão da escolarização, os PCN se constituem num currículo nacional, pois se configuram em apenas um documento para todas as escolas do território brasileiro.

Os PCN se propõem a definir apenas diretrizes para auxiliar na construção de currículos específicos para cada realidade educativa, entretanto, essa justificativa não coincide com os efeitos de verdade que os PCN construíram em torno de si mesmo, pois ao se colocarem como parâmetros, mas com orientações didáticas, avaliativas, metodológicas específicas, pretendiam garantir relações de dominação e efeitos de hegemonia dos conhecimentos reduzidos às disciplinas curriculares e considerados válidos e as formas sancionadas de agir e viver em sociedade. Dessa forma, os PCN colocaram em exercício ações biopolíticas do Estado brasileiro, ao definir saberes e competências para atingir os estudantes em todo o território nacional. Tal reforma curricular se deu aos moldes das reformas curriculares implementadas na Espanha, Argentina, Estados Unidos, Inglaterra, seguindo os princípios do neoliberalismo e dos organismos internacionais que financiam a educação mediante algumas condições (MOREIRA, 1996). Podemos afirmar ainda que, a partir da globalização, se construiu uma estratégia de biopoder na educação de proposições internacionais, pois as reformas curriculares em sua maioria seguem as mesmas diretrizes do neoliberalismo e dos organismos internacionais ${ }^{8}$.

8 A educação brasileira nos anos 1990 passou por um conjunto de reformas que seguem as diretrizes da reforma geral do Estado realizada no Brasil, entre 
Pensar o currículo como uma tecnologia de poder disciplinar e com dimensões biopolíticas permite problematizálo a partir das relações de poder que o constituem e compõem correlações de forças para formar pessoas, forjar subjetividades. Permite ainda analisar o currículo como "[...] uma prática social, discursiva e não-discursiva, que se corporifica em instituições, saberes, normas, prescrições morais, regulamentos, programas, relações, valores, modos de ser sujeito" (CORAZZA, 2001, p. 10). Como um dispositivo de saber-poder-verdade o currículo não pode ser visto como um artefato neutro, desinteressado, porque está implicado naquilo que nos tornamos, nos modos de subjetivação. Ou seja, o que o sujeito é, aquilo que nós somos, é histórica e culturalmente contingente, pois não há natureza em um modo particular de ser já que esste é determinado e constituído pelos discursos construídos em diferentes âmbitos, inclusive no currículo.

Contudo, os PCN são pensados a partir da teoria educacional crítica que arremete contra a ordem instituída pelo capitalismo, mas é ainda tributária da "[...] crença no sujeito centrado, cognitivo, racional, coerente, fonte e origem do pensamento e ação" (SILVA, 2002a, p. 10). No centro do discurso educacional crítico está um sujeito crítico “[...] [que] não apenas [é] capaz de ver e analisar a sociedade de uma forma transparente, desde que apropriadamente equipado com as armas da "crítica", mas também de transformá-la radicalmente" (SILVA, 2002b, p. 09). Apropriando-se desse discurso os PCN entendem a escola como grande responsável pela construção da cidadania, por combater as atrocidades do mundo moderno, objetivando uma sociedade mais "justa". Dessa forma, os

elas a promulgação da nova Lei de Diretrizes e Bases (Lei 9394/96), a Lei do FUNDEF (Lei 9424/96) e do Plano Nacional da Educação (Lei 10.172/2001), a Lei $\mathrm{n}^{\circ} 9.131$ de 24 de novembro de 1995 que instituiu o Conselho Nacional de Educação (CNE) com função de atribuir normas, deliberações e assessoramento ao Ministério da Educação. Não é a intenção neste trabalho analisar os PCN. 


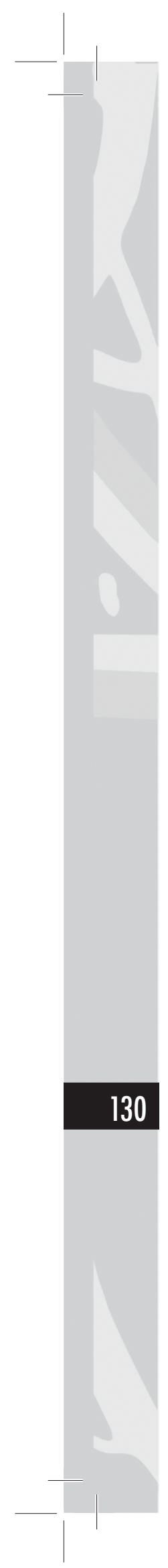

PCN são organizados em torno de dois eixos: as disciplinas tradicionais do currículo: Língua Portuguesa, Matemática, Ciências Naturais, História, Geografia, Artes, Educação Física e Língua Estrangeira e os temas transversais: Ética, Saúde, Meio Ambiente, Orientação Sexual, Pluralidade Cultural, Trabalho e Consumo (BRASIL, 1998).

A concepção dos temas transversais fomentou a organização de disciplinas que compõem a parte diversificada do currículo escolar, como forma de trabalhar questões específicas supostamente silenciadas pelos demais componentes curriculares. No CSFX, essa concepção foi assumida para justificar a criação do componente curricular Aspectos da Vida Cidadã (AVC). A seguir analisamos o componente curricular Aspectos da Vida Cidadã.

\section{A constituição do componente curricular Aspectos da} Vida Cidadã (AVC) e a constituição de subjetividades cidadãs

O componente curricular do ensino fundamental Aspectos da Vida Cidadã (AVC) tem adquirido centralidade nas escolas que funcionam em Regime de Convênio com a Diocese de Abaetetuba, entre elas o CSFX, no qual ela é apresentada no Projeto Político Pedagógico (PPP) como o grande diferencial do colégio. As condições de emergência do componente curricular AVC são marcadas por práticas que se caracterizam pela definição dos propósitos educativos do CSFX que se enuncia como uma instituição inovadora em relação à educação em outras instituições educativas. Essa ideia de inovação tem no componente curricular AVC sua possibilidade de concretização, pois esta é atravessada por discursos que tentam materializar o lema do colégio "Fé e Ciência", uma síntese de sua missão: "Formar, através de uma educação libertadora cidadãos com princípios éticos e cristãos, capazes de transformar a sociedade" (PPP, 2008, p. 03; PROGESTÃO, 2004, p. 63).

A ideia de acréscimos disciplinares ao currículo escolar é tributária de um pensamento sobre currículo pautado em perspectiva tradicional em que esste "[...] é pensado como 
um conjunto de fatos, de conhecimentos e de informações, selecionados do estoque cultural mais amplo da sociedade, para serem transmitidos às crianças e aos jovens nas escolas" (SILVA, 2003, p. 13). Essa condição de possibilidade se constituiu pelo fato de o CSFX evidenciar aproximações discursivas do discurso curricular oficial, pois suas referências são os Parâmetros Curriculares Nacionais, consideradaos a possibilidade de garantir a "qualidade" da educação a em nível nacional. Os PCN apropriamse do discurso pedagógico contemporâneo para designar a escola como grande responsável na pela construção da cidadania e o currículo como o locus para operar essa transformação.

Dessa forma, a organização curricular do CSFX assumiu a perspectiva de currículo dos PCN, ao adotar uma "lógica disciplinar", "[...] imprimiu uma ordem geométrica, reticular e disciplinar, tanto aos saberes quanto à distribuição desses saberes ao longo de um tempo" (VEIGA-NETO, 2002, p. 169). De tal modo, o currículo é duplamente disciplinar, pois articula disciplinarmente saberes e comportamentos: "[...] as disciplinas são partições e repartições [...] que estabelecem campos especiais, específicos, de permissões e interdições, de modo que elas delimitam o que pode ser dito/pensado e feito ("contra" o que não pode ser dito/pensado e feito)” (VEIGA-NETO, 2008, p. 47).

A criação de novas disciplinas curriculares pode ser pensada como uma tentativa de "repartir" os espaços e os tempos em que determinados saberes e comportamentos podem ser trabalhados. Tal divisão é respaldada pela LDB 9394/96 que determina que os currículos do ensino fundamental e médio, "[...] devem ter uma base nacional comum, a ser complementada, em cada sistema de ensino e estabelecimento escolar, por uma parte diversificada, exigida pelas características regionais e locais da sociedade, da cultura, da economia e da clientela" (Art. 26). A criação pelas escolas brasileiras de disciplinas para compor a parte diversificada tem sido corolário de uma tentativa de dar conta dos chamados temas transversais, instituídos pelos PCN e que foram pensados como alternativas no âmbito da "engenharia curricular" disciplinar, que "[...] admite tantas disciplinas, tantas especialidades quantos forem

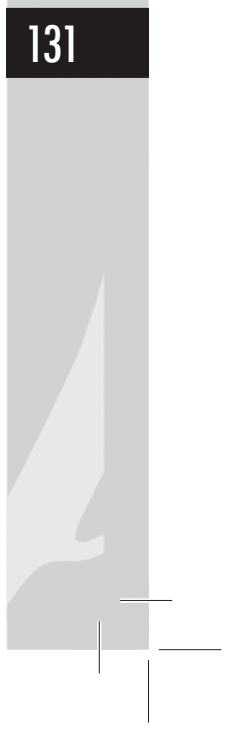




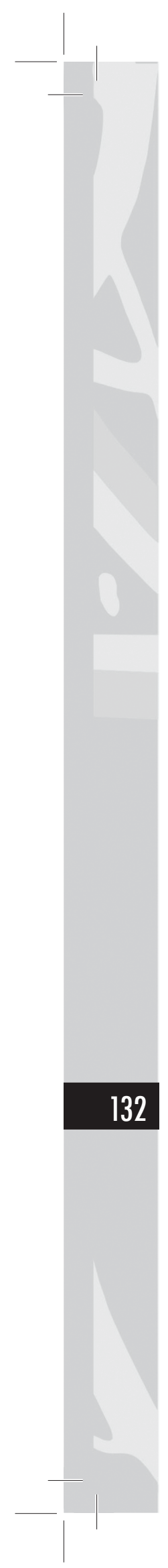

os casos" (VEIGA-NETO, 2002, p. 180). A instituição de temas transversais é uma tentativa de "resolver e recuperar (pela interdisciplinaridade) a pretensa unidade do mundo que teria sido quebrada na contemporaneidade" (VEIGA-NETO, 2002, p. 180) e ainda dar conta dos conjuntos de questões vivenciadas por crianças, jovens e adolescentes supostamente invisibilizadas pelas disciplinas comuns.

No ensino médio, o CSFX acrescentou em sua proposta curricular "[...] uma aula semanal de Ensino Religioso em todas as séries, bem como uma aula semanal de Ensino Religioso e Aspectos da Vida Cidadã na primeira e segunda etapa da Educação de Jovens e Adultos" (PROGESTÃO, 2004, p. 11) Conforme a diretora, os componentes curriculares AVC e Ensino Religioso, guardadas suas especificidades, são trabalhadas como complementares e o componente curricular AVC da proposta curricular do ensino fundamental é comparadoa com Sociologia e Filosofia componentes curriculares do ensino médio que trabalhariam as questões sociais, visando a construção de subjetividades cidadãs. Essa grade curricular diferenciada é citada em vários documentos: "O CSFX é a única escola no Pará a oferecer uma aula de Língua Portuguesa a mais e duas aulas da disciplina de Aspecto da Vida Cidadã e uma de Informática" $\left(\right.$ PROGESTÃO, 2004, p. 69) ${ }^{10}$.

9 A LDB 9394/96 determina no Art. 33 que o Ensino Religioso, de matrícula facultativa, constitui disciplina dos horários normais das escolas públicas de ensino fundamental, sendo oferecido, sem ônus para os cofres públicos, de acordo com as preferências manifestadas pelos alunos ou por seus responsáveis, em caráter: I - confessional, de acordo com a opção religiosa do aluno ou do seu responsável, ministrado por professores ou orientadores religiosos preparados e credenciados pelas respectivas igrejas ou entidades religiosas; ou II - interconfessional, resultante de acordo entre as diversas entidades religiosas, que se responsabilizarão pela elaboração do respectivo programa.

10 A Informática é trabalhada como disciplina e não como tema transversal sendo que a Diocese de Abaetetuba arca com as despesas de pagamento do docente da mesma. 
Essa "matriz curricular diferenciada" do CSFX foi aprovada pelo Conselho Estadual de Educação, Câmara de Ensino Fundamental, em 16 de Agosto de 2001, na qual AVC foi autorizado com uma carga horária anual de 320 horas, o que equivale a duas aulas semanais (45 minutos cada aula). A SEDUC criou um código especial para a lotação dos/as docentes contratados pela Diocese de Abaetetuba para trabalhar com AVC. Inicialmente AVC era trabalhado em conjunto com Informática, através do projeto de inclusão digital e social chamado de "Escola de Informática e Cidadania" (EIC). Essa articulação entre os dois componentes curriculares foi possível a partir da parceria do CSFX com o Comitê de Democratização da Informática (CDI) uma ONG que "[...] também trabalha nesta perspectiva de inclusão social dos menos favorecidos" (Projeto CDI). A EIC “[...] tem como finalidade promover a inclusão digital e social utilizando a pedagogia freiriana" (Projeto CDI). Tal projeto pretendia promover a interdisciplinaridade por meio de “[...] conteúdos significativos de formação ao exercício e construção de cidadania" (Projeto CDI).

Os dois componentes curriculares fazem um forte apelo à constituição de subjetividades cidadãs fundamentando-se em pressupostos da educação popular, sobretudo aqueles ligados à educação libertadora de inspiração cristã, que fazendo a crítica às estruturas sociais vigentes pretende atender as necessidades educativas das classes populares aliadas à construção de princípios cristãos que contribuiriam com a formação moral e ética dos/as alunos/as. A articulação entre esses componentes curriculares é justificada da seguinte forma:

Ressaltamos que essas disciplinas extra-curriculares são embasadas nas diretrizes curriculares, nos Parâmetros Curriculares Nacionais e na própria filosofia da escola que é "Formar através de uma Educação Libertadora, cidadãos com princípios éticos, cristãos, capazes de transformar a sociedade". (PROGESTÃO, 2004, p. 42)

Para atender os objetivos propostos pelos componentes curriculares a Diocese de Abaetetuba contratou duas pedagogas 


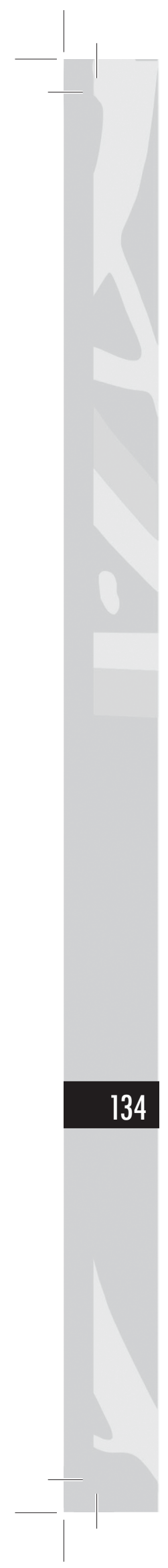

com formação e experiência que correspondem aos critérios que incluem conhecimento e engajamento religiosos e sociais, como exposto por uma das professoras do componente curricular AVC:

[...] me convidaram pra trabalhar, com essa disciplina [AVC] [...] ela trabalha com vários aspectos sociais, religiosos; então ela trabalha com todos os âmbitos da sociedade, então os pedagogos conseguem com certeza, administrar essa disciplina, porque geralmente dizem que a gente conhece de tudo um pouquinho, então me convidaram e eu aceitei e até hoje [desde 2003-2009] eu estou aqui trabalhando essa disciplina, gosto muito, me identifico muito com a disciplina.

Os enunciados sobre AVC indicam que sua edificação materializa uma forma de articular forças sociais, políticas, religiosas e educacionais das duas instituições a que o CSFX pertence. É um componente curricular, que se afasta do Ensino Religioso abertamente confessional e se aproxima das exigências educacionais das teorias educacionais críticas, ao enfatizar a formação cidadã dos sujeitos discentes, sem, entretanto deixar de enfatizar a formação do "bom cristão" e do "cidadão de bem". Ao relacionar valores laicos e religiosos, AVC não significa apenas "equilíbrio" entre as demandas do Estado e da Igreja em termos dos saberes considerados necessários à formação da juventude e da construção de uma moralidade que regula os comportamentos e as condutas dos adolescentes e jovens em processo de escolarização, mas põem em exercício relações de poder que produzem tensões, alianças e disjunções entre os conhecimentos e valores laicos e religiosos.

A constituição de subjetividades cidadãs exige a ancoragem em alguns aspectos da pedagogia crítica que são acionados para justificar sua constituição, na qual se entrecruzam discursos da pedagogia crítica, que, segundo Garcia (2002), tem seus fundamentos numa "Antropologia socrático-cristã", e da Igreja Católica, que pensa a educação como uma missão para formar sujeitos éticos e cristãos a partir de valores humanísticos: 
[...] a disciplina Aspectos da Vida Cidadã foi pensada como uma temática que pudesse estar desenvolvendo a ética, a construção dos valores pessoais, dos direitos humanos, da convivência democrática, baseados nos quatro pilares da educação que são aprender a aprender, a fazer, a conviver e a ser a partir da observação de que os valores pessoais socialmente justificados em nossa sociedade e até mesmo dentro de nossas escolas não têem sido valorizado. (PROGESTÃO, 2004, p. 11).

Os discursos pedagógicos críticos acionados em AVC enfatizam a noção de um sujeito centrado, consciente, livre, autônomo, aos moldes do sujeito moderno instaurado pelo iluminismo para propor a formação de alunos/as críticos/as e cidadãos/ãs conscientes voltados/as para a construção de uma sociedade justa e democrática. Conforme Corazza (2001), o dispositivo de "cidadanidade" inventado pelo liberalismo do século XIX produz a cidadania como uma matéria moral a ser trabalhada para garantir a formação do sujeito moral cidadão que se comprometerá com a solidariedade, o respeito, a justiça e o diálogo que devem permear as relações sociais. Em um recorte dos documentos, o objetivo de AVC é enunciado da seguinte forma:

É trabalhar, e está trabalhando a formação dos alunos em vários aspectos, tanto no aspecto da formação como pessoa, dos valores, da família e dos comportamentos, a partir da sexualidade, da valorização do meio ambiente, então inclui todos esses assuntos porque eles precisam ter uma formação como cidadão. (Informação verbal ${ }^{11}$ ).

Quando inquirida se os outros componentes curriculares também deveriam trabalhar "os aspectos da vida cidadâ", a diretora afirma:

11 Informações prestadas pela diretora do CFSX à autora em pesquisa de campo, 2010.

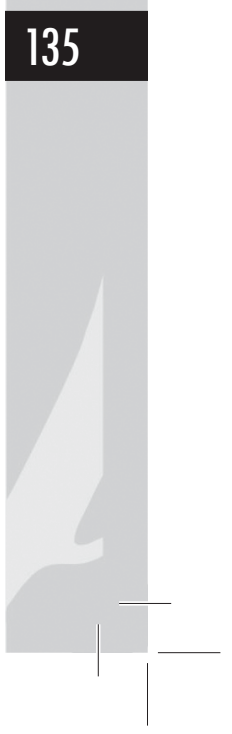


[...] mas a disciplina AVC reforça mais o respeito, a valorização, a convivência do dia a dia, na casa, no bairro, na comunidade onde o aluno está inserido, aqui dentro da escola, na sala de aula, é mais assim forte digamos assim, exige mais que o aluno centralize mais a questão com relação na sua mente, ao seu comportamento diário, isso que a gente tem mais assim pra reforçar. (Informação verbal ${ }^{12}$ ).

Nesse sentido, AVC tem como escopo mobilizar conteúdos em torno dos diversos aspectos que constituem subjetividades cidadãs, transformando-as em matéria moral do adolescente e do jovem que passa a ser "governado" por técnicas de administração e regulação da conduta que defendem a busca e a manifestação da verdade sobre o si mesmo. O componente pode ser concebido como um governante dos jovens e adolescentes, "[...] por ter sua prática conformada a um certo diagrama de forças políticas, e a um conjunto de tecnologias administrativas, que enunciam sua própria razão e a do Estado" (CORAZZA, 2001, p. 79). Os conhecimentos acionados em AVC conseguem governar jovens e adolescentes porque utiliza uma retórica que articula discursos científicos e religiosos nos diferentes temas que discute numa tentativa de "alcançar os jovens" como afirma uma das professoras de AVC.

De acordo com Foucault (2006), vivemos a "era da governamentalidade" em que táticas contemporâneas de governamento são utilizadas para "conduzir as condutas" dos sujeitos individuais e coletivos, nesse caso, de adolescentes e jovens em processo de escolarização ${ }^{13}$. Esse processo de

12 Informações prestadas pela diretora do CFSX à autora em pesquisa de campo, 2010.

13 Usamos a palavra governo não no sentido de "Governo do Estado (em geral grafado com $\mathrm{G}$ maiúsculo), isso é, essa instituição do Estado que centraliza ou toma, para si, a caução da ação de governar” (VEIGA-NETO, 2002, p. 19). Utilizamos governamento "nos casos em que estiver sendo tratada a questão 
governamentalidade visa transformar os indivíduos em cidadãos, num processo de regulação moral de si próprios e dos outros, pois "os cidadãos moldam suas vidas através das escolhas que fazem sobre a vida familiar, o trabalho, o lazer, o estilo de vida, bem como a personalidade e sua expressão" (ROSE, 1998, p. 43). Esse governamento dos adolescentes e jovens por meio do componente curricular AVC pretende administrar suas necessidades, para regular seus dilemas morais e seus comportamentos. É o que identificamos nos enunciados que justificam o componente curricular no Relato de experiência do projeto "Desmistificando a sexualidade em Rodas de Conversa” (2009).

[...] o CSFX acrescentou na sua grade curricular a disciplina AVC, objetivando com isso implementar especificamente no ensino fundamental $\left(\begin{array}{lll}5^{a} & a & 8^{a}\end{array}\right)$, práticas educativas que estimulassem os adolescentes a refletir e vivenciar experiências para além dos conteúdos escolares. Nesta disciplina são desenvolvidos vários momentos de aprendizagem, os quais são efetivados através da problematização, tematização e elaboração de intervenções sociais pertinentes às indagações ou problemas detectados na realidade contextual dos alunos/as ${ }^{14}$.

Ao destacar a relevância de AVC, os docentes e os gestores manifestam a preocupação em dar atenção especial aos adolescentes e jovens, por considerarem essa fase como a mais propícia para uma formação dos valores cristãos e cidadãos.

\section{7}

da ação ou ato de governar" (VEIGA-NETO, 2002, p. 19), isso é, quando se trata de "dirigir a conduta dos indivíduos ou dos grupos: governo das crianças, das almas, das comunidades, das famílias, dos doentes" (FOUCAULT, 1995, p. 244).

14 Relato de experiência do projeto: "Desmistificando a sexualidade em Rodas de Conversa". 
[...] a criança, muitas vezes chega na $5^{a}$ série e a gente observa os costumes que estão trazendo das outras escolas ou então da própria família, da própria sociedade em que ele está inserido, mas a gente assim quer ajudar, nesse momento fazer essa parceria com a familia, pra que essa criança, esse adolescente chegue à juventude com outro amadurecimento, mas é importante assim a gente frisar que no ensino médio eles continuam essa formação porque a gente vê assim o trabalho que o professor de Sociologia tá fazendo é uma continuidade que todos aqueles assuntos de $5^{a} a 8^{a}$ dentro das disciplinas Aspectos da Vida Cidadã.

O campo enunciativo do componente curricular AVC constitui-se de uma injunção múltipla de saberes e poderes, sujeito a debates históricos no meio educacional e religioso. Em AVC são produzidas injunções sobre diferentes práticas para constituir sujeitos que assumam em sua existência aspectos da vida cidadã, tanto laicos como religiosos, tais como consciência, liberdade, solidariedade e valores morais.

\section{Considerações finais}

A organização curricular do CSFX evidencia as correlações de forças entre as duas instituições a que o Colégio é conveniado, a Igreja e o Estado, constituindo práticas de normalização postas em funcionamento a partir de relações de saber-poder que incidem principalmente sobre os corpos individuais e coletivos dos sujeitos discentes no colégio.

Ao perscrutar os enunciados sobre o componente curricular AVC, observamos que esstes são marcados pela singularidade de um colégio com orientação laica e religiosa, em que as subjetividades são produzidas a partir dos princípios conjugados pela insígnia assumida pelo colégio, a articulação entre "fé e ciência", materializada em exortações, prescrições, aconselhamentos, proposições voltadas para a formação de subjetividades cristãs e cidadãs capazes de exercer domínio 
de si e contribuir com a transformação da sociedade. A trama discursiva construída nos documentos do CSFX e do componente curricular AVC constitui um complexo de práticas de governo das condutas dos integrantes da escola, na escola e para além dela, pois tais condutas são ampliadas para a comunidade.

\section{REFERÊNCIAS}

BRASIL, Secretaria de Educação Fundamental. Parâmetros Curriculares Nacionais. Brasília: MC/SEF, 1998.

BRÍCIO, Vilma N. de. Entre o controle e a transgressão: a construção escolar das diferenças entre os gêneros. Margens - Revista Interdisciplinar da Divisão de Pesquisa e Pós-Graduação do Campus Universitário de Abaetetuba/Baixo Tocantins/UFPA, Belém, Paka Tatu, v. 1, n. 4, p. 125-134, 2007.

CORAZZA, Sandra. O que quer um currículo? Pesquisas póscríticas em educação. Petrópolis: Vozes, 2001.

FOUCAULT, Michel. Microfísica do poder. Rio de Janeiro: Graal, 2006.

História da sexualidade I: A vontade de saber. Rio de Janeiro: Graal, 2005a.

Em defesa da sociedade. São Paulo: Martins Fontes, 2005b.

Vigiar e punir - História da violência nas prisões. Petrópolis: Vozes, 2005c.

A ordem do discurso. São Paulo: Edições Loyola, 2004. 
. O sujeito e o poder. DREYFUS, Hubert; RABINOW, Paul. Michel Foucault: uma trajetória filosófica. Para além do estruturalismo e da hermenêutica. Rio de Janeiro: Forense, 1995.

GARCIA, Maria Manuela A. Pedagogias críticas e subjetivação: Uma perspectiva foucaultiana. Petrópolis: Vozes, 2002.

LARROSA, Jorge. Tecnologias do eu e educação. In: SILVA, Tomaz Tadeu da (org.). O sujeito da educação: estudos foucaultianos. Petrópolis: Vozes, 2002, p. 35-86.

MAUÉS, Josenilda. Currículo sob a cunha da diferença. In: REUNIÃO ANUAL DA ANPED, 27. Programa e resumos, 2004.

MOREIRA, Antonio Flávio B.; SILVA, Tomaz T. Sociologia e teoria crítica do currículo: uma introdução. In: MOREIRA, Antônio Flávio B.; SILVA, Tomaz T. da (org.). Currículo, cultura e sociedade. São Paulo: Cortez, 1994. p. 39-58.

Os Parâmetros Curriculares Nacionais em questão. In: Educação \& Realidade, v. 21, n.1, jan-jun. Porto Alegre: UFRGS, 1996. p. 09-22.

POPKEWITZ, Thomas S. História do currículo, regulação social e poder. In: SILVA, Tomaz T. da. (org.). O sujeito da educação: estudos foucaultianos. Petrópolis: Vozes, 2002. p. 173-210.

ROSE, Nicolas. Governando a alma: a formação do eu privado. In: SILVA, Tomaz T. da (org.). Liberdades reguladas: a pedagogia construtivista e outras formas de governo do eu. Petrópolis: Vozes, 1998. p. 30-45.

SILVA, Tomaz T. (Org.). Documentos de identidade: uma introdução às teorias do currículo. Belo Horizonte: Autêntica, 2003.

Vozes, 2002a.

O sujeito da educação: estudos foucaultianos. Petrópolis: 
Mapeando a [complexa] produção teórica educacional Entrevista com Tomaz Tadeu da Silva. Currículo sem Fronteiras, v. 2, n.1, p. 5-14, jan.-jun. 2002b.

Os novos mapas culturais e o lugar do currículo numa paisagem pós-moderna. In: SILVA, Tomaz T. da; MOREIRA, Antônio F. Territórios contestados: o currículo e os novos mapas políticos e culturais. Petrópolis: Vozes, 1995. p. 184-202.

VARELA, Julia. O estatuto do saber pedagógico. In: SILVA, Tomaz Tadeu da. (org.). O sujeito da educação: estudos foucaultianos. Petrópolis: Vozes, 2002. p. 87-96.

VEIGA-NETO, Alfredo. De geometrias, currículo e diferenças. Educação e Sociedade, Campinas, v. 23, n. 79, p. 163-86, ago. 2002.

. Crise da modernidade e inovações curriculares: da disciplina para o controle. In: Encontro Nacional de Didática e Prática de Ensino, ENDIPE, 14. Anais. Porto Alegre: UFRGS, 2008.

VEYNE, P. Foucault revoluciona a história. In:

Como se escreve a história. 4. ed. Brasília: UNB, 2008. p. 237-285. 